that has been least interfered with. If the deformity is very great I exaggerate the effect of the tenotomy by inserting a suture over the inferior rectus tendon, and, having thus secured control of the eyeball, turn it outwards and fix it in this position by attaching the suture to the external canthus. This forced divergence of the eyeball is maintained for a day or two, according to circumstances, and the internal rectus, being compelled to attach itself further back on the eyeball, luses its power of abnormally converging the globe.

With regard to cases of divergent squint, I have endeavoured to simplify the ordinary, complicated, and somewhat formidable operation by merely shortening the internal rectus without interfering with the external. This is easily done by catching up the tendon on a book, exposing it, and freely separating its attachment to the sclerotic. I then seize the tendon with forceps and by two horizontal snips convert it into a narrow strip; the base of this strip is then transfixed by a needle armed with a thread, half an inch or more of muscular and tendinous tissue is cut off, and a firm attachment to the sclerotic immediately over the inferior rectus tendon is secured by perforation with a needle attached to the other extremity of the thread $;^{5}$ the two ends of the ligature are then carefully drawn together while the eyeball is turned inwards. Any amount of inversion may be thus obtained, only one suture is required, general anæstbetics may be dispensed with, and the operation admits of rapid execution. Of course, the external rectus may be adranced in obstinate cases of internal squint, or such advancement may form the first step of the operation, as in the practice of Professor Landolt; but it is useless, so far as my experience goes, to attempt to diverge the eye by advancing the external rectus unless you at the same time weaken par recul the internal rectus, and if you do weaken par recul the internal rectus you will very seldom find it necessary to resort to advancement of the external. It appears to me, therefore, that Professor Landolt's suggestion is to be deprecated: first, because be proposes to substitute in all cases of convergent squint a difficult and sımewhat complicated operation for one which is very simple and which admits of instant execution: secondly, because the external rectus, from its comparative length, tenuity, and diffuse attachment to the globe, is pecu. liarly unfitted either for advancement or resection; and thirdly, because any $\in$ ffect that advancement of the external rectus may have as an adjuvant to tenotomy of the inte nal in cases of convergent squint is more readily attained by simply fixing the eye outwards with a suture without interfering with the external rectus at all, and of course without any open wound.

\section{AN ESSAY ON CLINICAL UROLOGY IN INFANCY AND CHILDHOOD.}

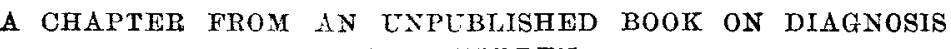
IN CIIILDREN

By FERNANDE; FIGUEIRA, M.D., EX-ASSISTANT OY THE PEDIATKICS CLINIC IN THE FACCLTY OF RIO DE JANEIRO.

THE functions of the urinary system are in full operation at the time of birth, because it is then organically complete, notwithstanding the anatomical peculiarities with which it is endowed in infancy. These peculiarities consist in the relative weight, size, and even different structure of the kid. neys from that in the adult, and in the different conformation and position of the bladder. The kidneys are proportionally more voluminous in the child than in the adult, for whereas the relation between the weight of the kidneys and the body is represented in the adult by $1: 1225$, these figures are in childhood 1:82-100, according to Huscke and Kölliker. They weigh from twelve to thirty grammes, and for about four years (the average time) they exhibit furrows on their surface, forming lobes, these lobes corresponding to the renal pyramids. The medullary substance predominates over the cortical, and, according to the calculations of Todt, this predominance may be indicated by the proportions $56: 21 \cdot 5$. The connexions and the position of

5 The conjunctiva is often so defective that it gives no support to stitches, therefore I suture the muscle to the tendinous insertion. the kidney do not present anything special, except that the suprarenal capsule which has approximately the form of a triangular pyramid covers the third part of the sarface of the organ. Contrary to what occurs in the a etht, Ballantyne thinks that the left kidney is not bigher or longer than the kidney on the right. The hilus corresponds to the leve? of the second lumbar vertebra The bladder in the child is oblong and acuminated, with its base rising to the pubic symphysis. The frequency of micturition in the early periods of life is caused by its small size. The anterior aspect has a triangulior form, which is not covered by the peritoneum and is in contaet with the abdominal parietes. In regard to function and structure, apart from the ureters and the external conformation of the genito-urinary organs of the two sexes, it ay sulce to say that there is a disposition rather urinary than genital. Catbeter No. 2 of the English scale (Ballanbyne), fits the urethra. The diseases of the urinasy system and the other organic local affections demand a practical knowladge of clinical urology, and this chapter of infantile semeiotice is as important as it is generally neglested either besause it is believed erroneously that disturbances of the urinary. functions are but infrequent in the child or beeause of the usual difficulty to collect urine necessary for examination. In order to collect the urine an indiarubber apparatus adapt. able to the sex of the little patient may be ased, or, failing this, a small catheter which does not cause the least danger when used with the necessary caution. It is preferable, at any rate, to obtain the urine by cathetexism than to keep a sponge in contact with the genitals, an old method which is especially unfit for microscopic examination. To my mind it is not to be recommended as a means for collecting urine for examination that the child showld be placed on an impervious sheet, from which the arine runs off, since this may imperil the health of the rittie boing ano it is far from a clean process. The same ritieism does not, however, apply to the advice of d'Espine and Piest, which may be thus summed up-namely, to make whenever possible, after an interval of sleep, methodica pressure over the bladder from ahove downwards. These anthors say that in doing so wine for analysis can be easily obtained, and that the process is so simple that nurses can practise it. A practical means to obtain urine is also to excite evacuation of the bowel by the aid of a suppository or a clyster, and at the opportune moment to gather the vesical contents, of which the emission, exept in. very rare cases, does not take place at the same time as defæcation (Dr. Olinto of Porto Alegre). All these proeedures are only neede $d$, as everybody knows, in the first period of life. Later there is the same simplicity of means as in the adult and, according to more or less early training, children naturally ask for opportunities to discharge the lowest neede of animal life.

First micturition.-The newly born child seldom empties the bladder whilst it is becoming detached from the maternal organism. After birth the fact of hours passing without the first micturition having taken place must nof be considerec abnormal, since this micturition is sometimes pexformed only after the child has been alive for twenty-fous and even fortyeight hours, and this without appreciable morbid cause This is because there is in such cases no retention of urine, but generally a lack of secretion, depending, according to some writers, upon the kind of alimentation. Thrs a child suckled at the breast of a nurse having a copious mammary secretion must imbibe more milk than the shild who takes his supply of nutriment from a feeding-bottle. Hence results a greater or smaller flow of urine. Berti has related some very interesting cases, which have not yet been fully studied, of urinary insufficiency in newborn babes.

Quantity. - The quantity passed in childhood varies according to age. The researches of Dobrn, Martin, and Ruge, for example, give from 8 to 9 cubic centimetres as the awount of each vesical evacuation in the newborn child, but according to Berti it is not possible, from variations in these amounts, to affirm anything as to the bealth of the child, nor do they indicate anything respecting the secretion of the following days. All that can be affirmed as a general proposition is that in relation to every kilogramme of weight the newborn infant passes four times as much urine as the adult. In the first five days the nocturnal emission seems to be less than the diurnal emission. During the first ten days the quantity is about 50 cubic centimetres each time and increases with the increase in suckling if the latter is done in a regular manner. According to the data of 
Parrot, Cruse, Comerer, Martin, Ruge, and other observers, between 200 and 500 grammes are the average diurual quantity of urine of a child aged from one month to two years. In sixty children of both sexes, from six to fourteen years old, Herg found from 550 to 1400 cubic centimetres to be the daily quantity, and Camerer found from 619 to 1034 in individuals from two to eleven years old.

Average Quantity of Urine secreted at different Age Periods (Vierordt).

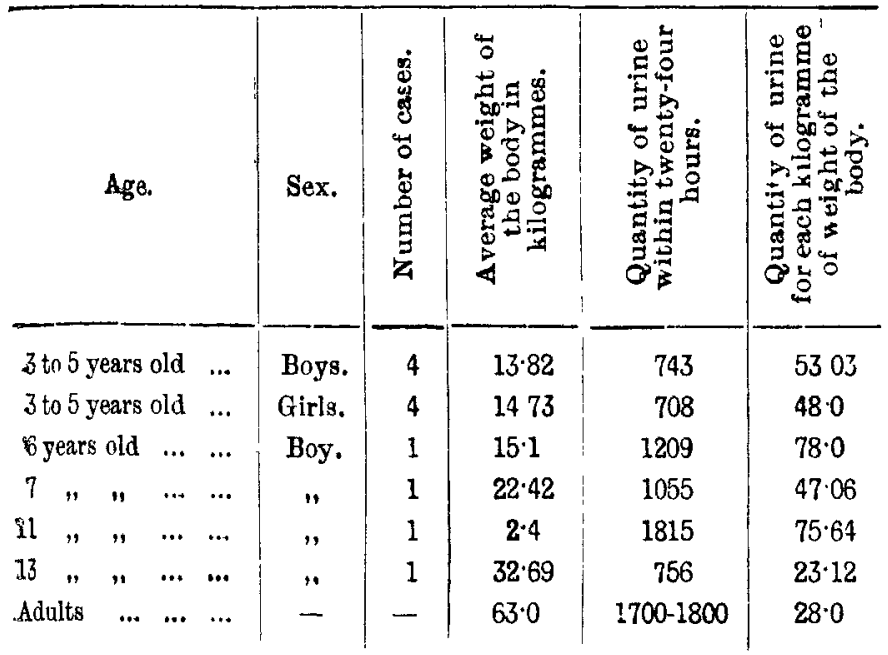

The number of micturitions during twenty-four hours in nurslings is from six to ten, and with a certain amount of practice the quantity can be estimated by examining the napkins. However, in cases of choleriform enteritis and even of intestinal catarrh the fæces become liquid and present an aspect identical wit' that of urine, and in order to distinguish them from the urine it is necessary to recollect that the stain of the vesical excretion has no regular configuration, spreads indeterminately through the cloth, whilst the spot formed by the frees is more or less circular and central. From the quantity, frequency, and ease in micturition some spmptomatic indications can be inferred. Incontinence is normal in the first months of life. The healthy .child which thrives on suckling generally passes urine and sleeps as soon as it leaves the breast of the nurse. With rare exceptions, as in meningitis and occasionally in dothienenteritis, retention is rare in childhood according to Roger. Retention occurs in surgical lesions of the urinary organs as it does in bysteria, in which there is likewise oliguria or polyuria. Dysuria is generally manifested in the course of pyrexia or is caused by phlegmasia or congenital diseases of the urethra, by phimosis or adhesion of the nymphæ. Pollakiuria is not peculiar to children. Vogel describes a spasmodic ischuria which is frequent in the first periods of life in little patients who suffer from intestinal dyspepsia. A reduction of the volume of urine is present in cardiorascular asthenia, in hyperthermia, in diarrhœea, specially in infantile cholera, and in partial impermeability of the kidney, as in urremia from nephritis. The contrary phenomenonpolyuria-which was formerly considered as rare, is shown by modern research not to deserve this epithet. It has been observed that after the re-absorption of extensive dropsies in nephritis, in saccharine diabetes, and in insipid diabetes, "which is chracterised by polydipsia and simple polyuria, the arine may attain the quantity of ten litres in twenty-four hours in children eight years of age.

Observers in Brazil assert positively that anuria is very seldom found in cases of yellow fever in children, but Juan Guiteras, who, in Guatemala, stu lied icteroid typhus fever, thinks that anuria is only less frequent in the child tban in the adult. This symptom may also appear in diphtheria as a precursor of death: albuminuria, vomiting, suppression of the arinary secretion and fatal issue-such is the ordinary succession of the phenomena according to Goodall. Enuresis -an involuntary and nocturnal emission and sometimes diurnal - is peculiar to childhood, and it is not sare to see it continue until puberty. It is the business of the practitioner to ascertain its causes, which sometimes depend on neuropathic inheritance (or transmission), at others on affections of the cerebro-spinal axis and of the urinary system and even on saccharine diabetes. The incontinence observed in female children is ascribed by Marion Sims to smallness of the bladder, caused by bypertrophy of the muscular coat and by the consecutive dimination of its capacity. Dr. T'uwnsend, who some time ago called the attention of practitioners to incontinence of urine in young children ${ }^{\text {and }}$ to its multiple etiological factors, has collected in a recent work some 100 critical observations. Fifty of each sex were patients from two to fourteen years old, 48 had nocturnal enuresis, 2 diurnal enuresis, 47 had the two kinds of enuresis, and 3 added to this rectal incontinence. Dr. Townsend indicates the following causes in the 100 patients whom he observed. I. Malformation of the bladder and urethra: epispadias, narrowness of the meatus, 2. II. Atony of the vesical sphincter: general weakness and anæmia, 17. III. Incontinence tbrough reflex irritation- $(a)$ increase of the quantity of urine: xephritis 1 , diabetes $0 ;(b)$ alteration of the quality of urine : excess of urates and of uric acid 2 , excess of acidity 3 ; (c) vesical calculus $0 ;(d)$ hyperexcitability of the genitals proceeding from-phimosis 11 , adherence of the prepuce with or without retention of smegma and balanitis 22 , vulvitis 1 , masturbation 1; (e) irritation of the anus: through intestinal worms 6 , eczema 1 , polypus of the rectum 1 ; and $(f)$ irritability of the bladder from unknown causes 31. Freud found at least in balf the patients suffering from enuresis an exaggeration of the muscular tonus of the lower limbs. The child being seated naked on a table if an attempt be made to separate the legs, which are hanging down, the separation is attended with great difficulty; and. left to themselves, the limbs come into collision violently, the heels knocking against one another.

Density. - The urine of the newborn child collected by catheterism was found by Dohrn to give a density of from 10028 to 10060 . Biedermann fixed the following figures for the first ten days of life : first day, 10100 ; second day, 1010.0 ; third day, 10090 ; fourth day, 10045 ; fifth day, 10060 ; sixth day, 10048 ; seventh day, 1005.5; eighth day, 10037 ; ninth day, 1002.4; and tenth day, 10027 . From the first week the specific gravity diminishes in proportion as suckling is regular, and although the figares given by Bischof, Camerer, Hecker, Picard, and others are still too imperfect to lead to a definite conclusion, it seems certain that the density of the urine in the first and second periods of childbood does not attain the average figure of the adult. The variations appreciable by the urinometer in disease, nervous affection, nephritis, \&c., have no semeiological significance in the child, for the density follows proportionally oscillations in amount of urea. Martin and Ruge recommend that in early childhood the coefficient 2 or $2 \cdot 33$ (according to Hasser) which is used in the calculation of solid substances in the urine of the adult be replaced by $1 \cdot 6$.

Colour.-The colour of the urinary liruid becomes darker from pale yellow in the newborn child as the child loses its weight and turns to its original hue after the sixth or eighth day. The urine extracted by catheterism in the first week is paler than that which is passed naturally. This fact is recorded by Martin and Ruge, and Professor Vierordt, relying on experiments made at the Kaupp Institute, explains it in the following manner. When little water is passed there is much absorption by the bladder of the water contained in the urine and the latter thus does not remain so clear. Respecting the significance of the changes of colour there is nothing to modify in what is known on these in the adult. Bile dyes the urine greenish; the blood-red with several changes; santonine-dark yellow, which is soon transformed into carmine ; methyl-blue--light blue; carbolic acid,--black, \&c. In physiological conditions the urine is clearer during the period of suckling than after weaning owing to the change of diet.

Transparency.-The transparency diminishes much in the first days of life, because the urinary liquid contains sediments with vesical epithelium, uric acid, and even albumin, but this perturbation does not last long and it has no pathological character. When left to itself the child's urine gets opaque more easily than the adult's ; this is caused by the growth of inferior organisms.

Odour.--In proportion to the age, from inodorous in the newborn babe it gradually acquires the peculiar smell it has in the adult.

Reaction - - The urine of the nursling, which is generally neutral or occasionally alkaline on the first day or first few days which follow the kirth, according to Professor Parrot appears nearly always neutral, and acidity, however slight it may be, must always make one suspect a defect in the alimentary 
system of the child. Cruse accepts this statement, whilst Martin and Ruge describe a slight acidity in three-quarters of the cases in fresh urine at the first and in the remainder of his observations a feeble alkalisation or a neutral reaction. The "urina sanguinis" is more acid than that passed during the day, which is called " urina potus," and the acidity is frequent in sclerema and in infantile atrophy.

Urea.-Dohrn found thirty-six milligrammes of urea in the bladder of a child which was just born, and Martin and Ruge determine the following quantities during the first ten days of life : $-0.0763,00783,0.2504$, $0.1827,0.1358,0.1817,0.2567,0.2284,0.16240$, and 0.1505 . The urea goes on diminishing progressively with lactation, although it is relatively very plentiful up to the first month ( 0.80 for a litre per kilogramme of child, according to Parrot) and amounting during the third week to 1 gramme and 1.89 grammes. Until eleven years of age Camerer determined from 11.1 grammes to $15 \cdot 1$ grammes, and generally speaking we may assert that from the second year up to puberty the figure is 1.7 per cent., and therefore it is less than in adults. The urea-which has in the child the same physiological signification as in the adult-is likewise influenced in its production by indigestion of albuminoids as Schabanowa demonstrated. However, the newborn babe, swallowing in twenty-four hours twice as much nitrogen as the adult, excretes in urine six times less, although there is approximately the same amount of oxygen. "He burns less, absorbing more fuel and the same quantity of oxygen," the daily increase of weight explaining this excess of assimilation over de-assimilation. Temperature acts also in influencing the amount, so that the colder the newborn babe becomes the less urea he excretes. Respecting weight, however, we must observe with Professor Parrot: "Generally speaking, the urine of children from one to thirty days old contains per litre so much the more urea in proportion as the weight is greater: but although rising in the same way the urea does not increase in proportion with the weight, so that a heavy child will give per kilogramme of its weight less than a lighter child, although the quantity of urea, estimated in litres, is more considerable in the first case." Besides diseases common to the adult urine deposits urea in athrepsia and sclerema. Azoturia is common, but not the hypo-azoturia, which, according to Money, forms a feature of the symptomatology of gastric catarrh, the skin losing its elasticity as in infantile cholera.

Uric acid.-A regular element in the urine of the newborn babe, which increases during the first three days and diminishes afterwards, is uric acid. And in spite of oscilla. tions during twenty-four hours at that epoch it is certain that the proportion between this product and urea is greater than in the previous period, although the proportion between the acid excreted and the weight of the body is approximately the same in the adult as well as in the child. Derivatives of uric acid are found in a newborn child's urine such as urates and allantoin. Wohler determined their presence, in the same manner, in the urinary excretion of animals which were just born. Sometimes in the foetus, although oftenest in the child from the first to the seventh day, there exist in the kidneys, never in the cortical sub. stance, in the lower half of the pyramids, converging towards the hilus, more or less notable sediments of light yellow or dark yellow material. These sediments, which obstruct some straight tubes and which are moulded by them, constitute the infarcts of uric acid spoken of by Virchow, and which besides this substance contain oxalate of ammonia and epithelial detritus. It appears that the opinion which at first attributed these infarcts to albuminuria is gaining ground again, and Sutherland even thinks that other forms of albuminuria (called physiological) of childhood, such as the cyclical, the albuminuria of adolescence, and even paroxysmal hæmoglobinuria, must belong to the uric diathesis. West asserts, and it is a current doctrine, that under the action of cold, of gastric disturbance, of fever, and probably of an hereditary tendency, it happens frequently that the urine of children deposits uric acid. Such sediments are transitory and may cause colic and dysuria or even suppression of excretion for some hours. Bokai thinks that the irritation of the neck of the bladder by free uric acid together with the renal infarct: are two of the etiological factors of the state described hy him under the name of vesical spasm, which Vogel calls spasmodic ischuria, and which West and several writers describe. It is the cystospasm, the "Blasenkrampf" of the Germans. Bouchut is of opinion that the uric gravel of the first days of life is physiological, but disappears afterwards. The frequency of calculus in childhood is well known, and by this may be understood the variable intensity with which the uric diathesis appears at that age, and which Sutherland thus describes. It is seen in children of special conformation, who are lean, nervous, have disturbed sleep and exaggerated senses, are very sensitive to cold, and perspire on slight canse. As objective signs we observe an irritable pharynx. the tonsils and adenoid tissues are hypertrophied, there are headacheand intestinal catarrh with furred tongue, the spleen and the liver are enlarged, the pulse is weak, slight, and irregular. A symptom of great value is the pain which accompanies the excretion of uric acid; this pain may be seated in any part of the urinary system or umbilical region, and may be piercing, like that of renal colic in the adult, and may even awake the child, who begins to cry with angaish, and who has nausea and vomiting. According to the analysis of Gauthier the urine of children nourished by a wet nurse contains more uric acid; deposits of that substance are found in the form of brick-coloured sand in the folds of the napkin or at the bottom of the chambers.

Hippuric oxalic, benzoio acids, and creatinine.-The urinary liquid first passed contains very small quantities of oxalic, hippuric, and benzoic acids and its compounds, but the presence of some of these in the urine of the newborn babe is denied by Cruse. It is known, and I repeat it, that oxalate of ammonia enters into the composition of the infarcts of Virchow. Hofmann says he never found creatinine.

Colouring matter.-A few years ago there was much work done respecting the presence of indican in the urine of tuberculous children. The initial work belongs to Hochsinger of Trienna, who endeavoured, in a remarkable communication, to demonstrate to the Pædiatric Congress of Bremen in 1890 that urine which is rich in indican among children from one to six years old is a symptom of tuberculosis. The great importance of such a statement would have been marked if later observations had confirmed it, and hence the interest attaching to Krause's researches. In this research is to be found a detailed report of the cases which served as a basis for Hochsinger's conclusions. We see from that. monograph that in the majority of the cases there was only one application of the tests for indican, and the experiments of other authors gave results opposed to those of the famous Vienna physician. W. Steffen, among 19 children from one and a half to fifteen years old who were clinically and bacteriologically tuberculous, examined the urine 1203 times, and in these analyses be failed to find indican ' 718 times. he met with traces in 195 instances, small quantities in 146, average quantities in 86 and in 58 large quantities. This difference in results may be ascribed to the difference of age, but Steffen divided his cases into groups, and in the first group of 9 children from one to six years old, like those of Hochsinger, 654 examinations of urine gave the following data: 372 times no indican at all, 120 times traces, 94 times little indication, in 42 instances an arerage quantity, and in 26 a large quantity. On the other hand, Voute, using Jaffe's method modified by Stokris of Amsterdam. submitted to examination the urine of 71 children from one to nine years old, divided into two series. The first series, composed of cases of latent and masked tuberculosis and of scrofulosis, gave in 51 analyses for 37 cases: no reactions at all, 13; weak reactions. 27; average, 15 ; and marked, 6 . In the second series of 34 cases the urine of children suffering from diseases of the digestive system \&c., being analysed 42 times presented 10 cases without reaction, 11 weak, 10 average, and 11 marked reactions. C. Giarré, using Jaffe's and Obermeyer's method, sought for indicanuria in 49 children from one to ten years old who were evidently tuberculous, and these are the results which he describes. 1. Traces of indican are found in children's urine in several diseases, among which is tuberculosis. 2. The increase of indicanuria may be obserred either in tuberculosis of the first period of childhood or of the second, and chiefly in relation to serious entero-peritoneal lesions, pulmonary cavities, and acute miliary tuberculosis, but this relation cannot be considered regular. 3. The increase of indican in the urine may even be wanting in the most typical forms of tuberculosis of the first period of childhood. 4. A remarkable increase of indicanuria may appear in children, no matter how old they are, in othey diseases which involving the digestive organs or other parts of the body increase or facilitate the decomposition of 
albumiroids. 5. Non-tuberculous athrepsia and chronic lesions of the respiratory organs which are not specified, of which the diagnosis from tuberculosis offers difficulties, may be accompanied by indican in the urine. Money, while investigating affections of a non-tuberculous nature, found indican to be frequent in albuminuria, in diseases of the intestine, and in serious inflammatory diarrhcea, contrary to Senator, who declares indicanuria to be very rare in childhood. Steffen determined its absence in 5 healthy new-born children, and in patients from one to six years old he obtained these proportions: diphtheria and typhoid fever (which, it is well known, is mostly mild in the child), $1: 5$; measles, $1: 3$; and in 60 cases of pneumonia, bronchitis, kidney and heart affections, ${ }^{\circ}$ rachitis, and enteritis indican was found scantily 13 times. Nomidlowski-studying indicanuria in the famous laboratory of Epstein, to which pædiatrics owes so much-found its reaction in the urine soon after birth, even in the absence of digestive disorder, and he observed it also, althongh very seldom, in suckling babes who had mother's milk. In sucklings fed on mother's milk and cow's milk, still without apparent gastro-intestinal disorder, indican is frequent; the latter has always been found in gastro-enteric disorders, and the gravity of these disorders is in direct proportion to the intensity of the indicanuria. In the second period of childhood indican has the same semeiotic value as in the adult The same observer affirms that there is no relation at al between indicanuria and infantile tuberculosis. This is also affirmed by Gehlig in his work presented to the Congress of Rome. Respecting other points be says : (a) healthy suckling babes who are fed with sterilised milk and who are not subject to digestive disturbances sometimes present traces of indican in the urine, and (b) if digestive disturbances take place indican is nearly always found, and its quantity increases with the gravity of the disease. Indicanuria is particularly prominent in chronic catarrh of the intestines, in cholera, and in typhoid fever. In older children not suffering from digestive derangement the urine contains normally some indican. If the diet contrins much nitrogen the indicanuria becomes more marked. Jahn is still one of those who do not attach the least value to the presence of indican in the urine for the diagnosis of infantile tuberculosis. The figures given by this author are striking; he studied the reaction in surgical tuberculosis in the laboratory at Bâle. He found normal urine or urine with traces of indican in 38 per cent. of cases with multiple lesions and in 39.4 per cent. of cases with one focus. This proves that the extension of the lesion has no significance. When indicanuria was marked the percentage appeared also little higher in the cases with multiple foci. Jahn affirms, however, that indicanuria is more frequent in tuberculosis than in other affections. Miss Lioubitza Diouritch asserts this much more decidedly in her thesis, of which I transcribe the conclusions. 1. Indican exists in a normal state in the urine, but in such a small quantity that indicanuria may be considered as pathological, especially in children whose diet has less nitrogen than that of adults. 2. As the indican proceeds from indol, indicanuria will manifest itself chiefly in diseases which are accompanied by an over production of indol. 3. This extra production takes place chiefly in diseases of the digestive tract, acute and chronic. 4. Indicanuria is found also in certain acute diseases such as typhoid fever, pneumonia, bronchitis, chorea major, and diphtheria. 5. It is constant and permanent in tuberculosis. It appears, then, that there is a close relation between tuberculosis and indicanuria. This fact is of some importance in cases where the diagnosis of tuberculosis is difficult. 6 . It is not easy to give an explanation of its appearance in tuberculosis when there are no digestive disturbances. It can be explained to a certain extent by the profound disorder of general nutrition which manifests itself in the course of tuberculosis. Of all the investigators quoted, only Djouritch supports the observations of Krause and Hochsinger. Steffen, Voute, Giarré, Jahn, and Gehlig operating in different conditions are opposed to the special significance of indicanuria in the diagnosis of infantile tuberculosis. It does not seem to me that the matter needs much revision in order to establish a final conclusion, since I incline to the opinion of the majority of the observers; however, I presume that not sufficient stress was laid upon the alimentary or morbid factor which causes tuberculosis without apparent gastro-intestinal lesion to be marked by indicanuria. This is the point upon which the light of further critical researches must be projected.

Toxic power.-Solaro made experiments in order to determine the toxic co-efticient of the urine of healthy children. Injecting into the veins of rabbits the urine of a girl three years old, of another four years old, of one eight and a half years old, and of one ten years old, he observed that the toxic quantity per kilogramme of animal was always higher than the average of 45 cubic centimetres, which was established in such cases for the urine of the adult. Chamin, employing urine of suckling babes fed with mother's milk for injections in rabbits, found that 82 cubic centimetres per kilogramme were sufficient to kill an animal. The urotoxic co-efficient would be then 0900 and within twenty-four hours a new-born babe would excrete enough urine to intoxicate an animal of equal weight. I do not know of any work in prediatrics dealing with the special determination of the five prisons of Bouchard, which are still imperfectly studied, and of urea and of potash considered from this point of riew.

Chlorides, phosphates, and sulphates.-In nurslings there is always a small quantity of phosphates, of chlorides of sodium, which vary with alimentation. There are also in various proportions sulphates of sodium, potassium, calcium, and magnesium, which Lehmann and Lecanu believe to exist abundantly. In rickety subjects azoturia and excretion of phosphates go together, apart from the therapeutic influences which cause these urological figures to vary (Bezy). Mongour obserred, after injections with anti-diphtheritic serum, a reduction of chlorides and an increase of density, of diuresis, nitrogen, and phosphates. In athrepsia there is a great abundance of phosphates, but investigations upon free sulphuric acid at present show nothing.

Albumin.-As regards albumin, we find that the attention of investigators has always been attracted by a product whose significance has in childhood a special feature. In the child, indeed, cases of so-called physiological albuminuria are more frequent and the physician must know this in order to avoid great mistakes in his diagnosis. Martin and Ruge found albuminous urine in new-born children without lesion in the kidneys; and Mensi, in a hundred observations at the same age, found albuminuria nearly always and in a proportion of from 1 to 30 per cent., whilst after the fifth to the tenth day of life the phenomenon does not recur. Dohrn had already described albuminuria in the first hours of extra-uterine existence ; this appears to be now incontestable in spite of the negative results obtained by Robin and Parrot in sixty children examined. The phenomenon is explained by Martin, Ruge, Virchow, Henoch, and Baginsky as due to infarcts of uric acid; Ribbert, like Lecorché and Talamon, believes it has something to do with the persistence of the foetal state of the glomeruli and the continuance, therefore, of the process of renal transudation; and, finally, Bartels believes that in the interval which divides placental respiration from complete pulmonary respiration there is a diminution of oxygen so that intra-organic oxidation does not produce uric acid and in consequence is incompletely effected. Dohrn, Martin, and Ruge found in this albuminuria but a small quantity of albumin. Cruse never found it beyond the tenth day, but Ribbert says it may be considerable. Such an albuminuria, of which the pathological importance is nil, is said by Bartels to coincide usually with a certain degree of renal hyperæmia that does not otherwise affect a favourable prognosis. But in the new-born babe also albuminuria appears sometimes as a symptom of acute nephritis or of the very uncommon chronic idiopathic albuminuria of West, of which the anatomical basis may even amount to the white kidney, of which the gravity is well known. Nervous and hereditary albuminuria and that . which is caused by the action of certain medicaments also belong to the so-called physiological albuminuria. In the category of nervous and hereditary albuminurias are included nearly all those in which there seems to be operating a cause apparently of little importance upon an hereditarily morbid ground -i.e., on the one hand, the uric diathesis, as is now being generally admitted, and, on the other hand, the neuroses; these elements are sometimes combined. We have, for example, intermittent albuminuria and the albuminuria of adolescence of English authors. The first.named is characterised by dyspeptic disturbances, of which generative disorders are the etiological factors; it is the type found by Furbringer 9 times and by Leroux 19 among 60 and 330 children respectively from three to six years old 
and upwards. It appears sometimes only in the morning, and in another group from one to two hours after meals (because of the incomplete combustion of albuminoids, according to the assertion of Dluski); it is the "cyclic" albuminuria of youth of Pary, the albuminuria of growth of Eichhorst. Analysis never gives more than one gramme per litre, and the prognosis is always favourable. The albuminuria of adolescents, which is confounded with that of Eichhorst, manifests itself after muscular exertion and is believed sometimes to be caused by brain work, by over-study in schools. Besides this albuminuria, which is so frequent in neuropathic as well as in arthritic subjects, albuminuria appears transiently after baths and in the course of nervous affections. Cantharides and tincture of iodine, according to Jules Simon, and turpentine, copaiva, and cubebs cause the urine to become albuminous, and the same thing happens in persons with scabies due, says Unna, who is cited by Dluski, to the hyperæmia of the kidneys by cutaneous irritation favoured by vasomotor disturbances. In impetigo, in angina, in eczema, and in stomatitis albuminuria may appear without nephritis. According to Legendre this albuminuria is caused by disturbance of digestion with auto-intoxication and hepatic insufficiency, the latter producing-through the non-destruction of albuminoids and the non-detention of intestinal poisons-irritation of the liver. Except in circumstances lately determined it is very often difficult to say if the albuminuria depends or not on a serious kidney lesion, although this is easy in each individual case, thanks to the various characters of the albumins which are examined. In scarlet fever especially, and notwithstanding the studies of Sanné, there are still those who admit the principle of a normal simple albuminuria. Acute infectious diseases generally cause albuminuria to appear, slight and transitory, and this happens in eruptive fever, in typhus fever, in Siam disease, and in pneumonia; but it is also certain that, at a given moment, even in these morbid states the kidney may be very much injured, and analysis of the urine may have another signification. Nor do authors agree even respecting the temporary albuminuria of infectious diseases, which Lecorché and Talamon believe to be less frequent in the child than in the adult. In dothienenteritis Gubler always found it, Leube in 22 per cent., and Ekkert in 73 per cent. of the cases ; while Geier recorded 25 observations, and in every one of the cases there was nephritis, the albuminuria manifesting itself from the third day to the second week. In one of his valuable studies Binet always found this product in pneumonia and bronchopneumonia, in 1 per cent in pleurisy, in half the cases of tuberculosis of the lungs, and in two thirds of those of tuberculous meningitis. Albuminuria appears also in diseases of the digestive system from intestinal catarrh to cholera, in some quinsies, in nephritic colic, in athrepsia, seldom in rickety subjects, in tuberculosis, in leukæmia, and in atrophy. C. Herreira asserts "the great frequency of albuminuria in the febrile and apyretic malaria of children, in which very often the course of the phenomena closely corresponds to that of diffuse nephritis." Diphtheria affords an example of a transition between albuminuria due to functional and that due to organic disease, since in this disease in serious cases the presence of albumin in the urine is not by itself a proof of invasion of the kidney ; but this may happen occasionally some authors even admitting a primary diphtherial nephritis. Children may be attacked with acute nephritis and Bright's disease, and the examination of the urine yields the same indications as to albumin as in the adult; the frequency of sezondary, and especially of scarlatinal, nephritis is remarkable, cases of renal degeneration even in the first periods of life not being, however, very rare. Albumin is a constant element in chyluria. Respecting other albuminoid matters existing in the urine of the child researches are not numerous.

Hemialbuminose.-Hemialbuminose or propeptone, which appears sometimes in those suffering from Bright's disease, was found by Loeb in measles. In this febrile exanthem, "under the action of diazo-benzol, which is formed in the urine by the mixture of sulphanilic acid, of nitric acid, and of nitrite of sodium, the urine being saturated by ammonia assumes a characteristic scarlet colouration which tends a little towards orange colour" (Baginsky). Such a reaction is not connected with the fever, although it is generally more prominent on the disappearance of the fever, but it seems due to propeptone.

Peptone.-In 248 chlldren Binet found peptone in the urine
34 times-viz., in 5:28 pneumonia, $1: 2$ purulent pleurisy $1: 2$ severe febrile roseola, 10:37 diphtheria, $3: 21$ suppurations, 1:26 athrepsia, and 13:23 nephritis. Except two, in all the other cases there was simultaneous albuminuria, and peptone was always more frequent in the severe forms of diphtheria and nephritis. The researches of Arslan tend ta. prove the presence of peptone in the urine of those suffering from scarlet fever. I do not know, however, of any worke establishing the importance of the various kinds of peptonuria in diseases of children, the nephrogenic, the pyrogenic, the hæmatogenic, \&c., of Senator, Jaksch, Fischer, and others.

Fibrin and hemoglobulin.-There is nothing special to note respecting fibrin. Hæmoglobinuria manifests itself in a disease peculiar to the new-born child-viz, the very grave affection described by Winckel under the name of pernicious, icteric, apyretic cyanosis with bæmoglobinuria. Analysis of the urine shows, also, the presence of that product in. syphilis, where Reale found it in children twenty-two months. old, in poisoning by chlorate of potash, arsenic, or sulphuric acid, in chills, according to Demme and Lichtein, in scarlets fever according to Heubner, and in certain forms of malaria, as grave bilious fever, in which, as Laveran asserts, the microscope does not reveal corpuscles, but spectroscopic. analysis shows hæmoglobin. In the paroxysmal and intermittent form Mackenzie believes hæmoglobinuria to be the expression of paludism and Sutherland of the uric diathesis, whereas it is sometimes explained by the presence of nematoids (rhabditis, Baginsky); in other cases its pathogeny remains obscure.

Mucin.-To the existence of mucin, which is always: present in the urine of children of the earliest age, is ascribed by Cruse the fact that some observers have mistaken mucin in the urine for physiological albuminuria after: the first ten days of life.

Sugar.-Grape sugar was found by Pollack in the urine. of suckling babes, but researches by others, especially those of Bouchard and Parrot, tend to invalidate those studies. I must say, however, that the matter does not seem to me: to be exhausted, especially considering the imperfect results which are given by the reaction with the cupro-potassic: solution, in view of the very delicate tests with naphthol and chiefly phenyl-hydrazin. Examining with such means the urine of 51 healtby children from three to twelve years of age, Binet found in half the cases a quantity of glucose: amounting to a minimum of 0.20 per cent., and in the. remainder found slightly less or only doubtful indications. Grosz proposes to study in the clinical school of Epstein the: following questions. In what condition is glycosuria found in suckling babes and what is the nature of this sugar? Is there in early childhood an alimentary glycosuria such as is found in the adult? Very numerous researches were mades among children from one day to four weeks old; 24 were. healthy, 12 had chronic or acute gastro-enteritis, 10 were dyspeptic, 1 was hydrocephalous, and 1 was born prema. turely. As a result Grosz asserts that glycosuria does not appear in new-born babes in the physiological state, but "in certain digestive disturbances the urine contains a reducing; substance, not fermentable, possessing sometimes rotators power to the right, and giving very quickly positive results with sugar reagents; this substance disappears or persists for some time." In view of the studies of Dastre, who admits that milk sugar is transformed in the intestines into galactose through a special ferment, or in vier of the studies of Escherich, who accepts as a factor in that organic operation the bacterium coli commune, it is easy to understand that the glycosuria of children who suffer from digestive derangements is due to the non-transformation of the sugar in the intestines and to a decrease in the power of assimilation. Grosz determines other interesting points which cannot be: included in this paper, and affirms as a practical conclusior the presence of glucose in disorders of the infantile digestive. system, alimentary glycosuria, probably of milk sugar and its derivatives. Saccharine diabetes was until a few years ago nearly unknown in children when Kulz's statistics (111 cases) showed that this disease ought not to be considered such a rarity in children from six months to fifteen years old. Many facts are now available in science by Cantani, Jules Simon, Winckler, Berg, and Borgesio, who believes in a predilection of the disease for females. The quantity of glucose may be con. siderable in saccharine diabetes, of which the progress, assert Steiner, is faster in proportion as the patients are younger. Grape sugar has been observed, however, in other diseases. 
Demme showed it in pseudo-hypertrophy of the muscles, and limme in convalescence from scarlet fever, but in the latter Binet thought it was very seldom found, which contrasts with the frequency, as he shows, of diaceturia in that exanthematic pyrexia. And from 332 analyses by that observer of the urine of 161 sick children he concluded by showing the presence of glucose in grave diphtheria (27 times out of 38 cases), slight in tuberculosis and in nephritis (once in 16 cases). The constancy of glucose in the urine of grave diphtheria is ascribed by Binet not only to the profound intoxication of the discase, but also to asphyxia, since Droski demonstrated that a great number of substances provoke the increase of sugar, diminishing the quantity of oxygen, its fixation in the blood and its assimilation by the tissues. In this manner the field of asphy xial glycæmia must be enlarged, and, moreover, in diphtheria, as Regnard and Quinquand assert, the respiratory capacity of the blood is very limited, the latter imbibing 100 c.c. per litre, while in the individual in bealth that relation is represented by $240: 1000$.

Diaceturia.-As a symptom foreshadowing coma in sacsharine diabetes Jaksch recorded the elimination by the urine of acetic acid, its ethers, and its salts, a phenomenon which also presented itself to the author in various diseases and even as an independent morbid type which he called "diaceturia." The reactions of Gerhardt and Luhal are used in the analysis, and according to the assertions of Baginsky and Junon, excepting diabetes, diaceturia does not carry with it any serious prognostic meaning. Binet, who made a remarkable study on the matter, saw diaceturia 69 times in 150 children examined, 19:23 being pneumonias and broncho-pneumonias, $16: 26$ measles, $27: 34$ carlet fever, 4:4 erysipelas, $11: 31$ diphtheria, $2: 13$ suppurations, $2: 4$ typhoid fever, $2: 4$ tuberculous meningitis, $1: 1$ perityphlitis, $1: 1$ extensive burn, $2: 15$ acute nephritis, and $1: 1$ tumour of the iliac chamber. In the statistics the frequency of the reaction in eruptive fever is noteworthy.

Acetonumia.-It follows from the experiments of Baginsky that among bealthy children acetonuria is constant and without semeiotic importance. It is a substance very common in the urine in cases of eclampsia and with the temperature at $38.8^{\circ} \mathrm{C}$., vanishing with the disappearance of the fits and with the disappearance of fever.

Diazo-reaction. - In the hospital of St. Isabel in St. Petersburg De. Nissen studied the importance of the diazo-reaction among children. The patients, who numbered 462, were children from six months to sixteen years old, and the urine was submitted to analysis 2,500 times, the result being the certainty that the reaction is constant in measles, in typhoid ferer, and in miliary tuberculosis, existing or not in chronic pneumonia, in croup, in pleuro-pneumonia, pleurisy, laryngitis, tuberculous meningitis, diphtheria, erysipelas, and scarlet fever, and always lacking in other affections of the infantile nosology. In some diseases there are interesting peculiarities. In measles the reaction is constant-sometimes in the premonitory period, but nearly always preceding the eruption from twenty-four to forty-eight hours; this serves as a basis for the differential diagnosis from rötheln in which the diazo-reaction is absent. The latter persists throughout the fever or is co-existent with the morbillose exanthema or lasts longer than them. In scarlet fever the same thing does not happen and since the reaction coincides with the exanthem its diagnostic ralue is null. In abortive typhoid fever the diazo-reaction does not exist. In its other forms the characters are similar to dothienenteritis of the adult. In croupous pneumonia it lias no diagnostic importance. In pulmonary tuberculosis there are three hypotheses to take into consiaeration. 1. The diazoreaction is wanting or it appears at very distant epochs and it is little noticed. 'This is the case with caseous pneumonia and with the formation of caseous foci and carities. 2. The diazo-reaction appears at epochs more or less distant and ends by establishing itself finally a few months or a few weeks before death. This occurs in caseous jneumonia, accompanied with muliary tuberculosis. 3. The diazo-reaction is absent when bronchitis passes into a catarrhal pneumonia, afterwards it appears suddenly, very markedly, and continues until death. 'This is the case with miliary tuberculosis of the lungs. The diazo-reaction may then acquire a diagnostic value in certain cases of pulmonary tuberculosis, where diagnosis may be difficult." In 15 cases of meningitis there was reaction in 10 . The other cases were composed of 2 of meningitis affecting the brain and spinal marow and of three of single meningitis.
IIistological ol ments; pus.-Pyuria has the same signification as in the adult, excepting that described by Gee in childhood and temporary, with symptoms of cystitis and inevitable incontinence. The cessation of pyuria through the obturation of the ureter of the injured kidney is one of the most remarkable symptoms of suppurative pyelitis. The cells which are frequent in the infantile urine offer a character similar to those indicated in the urology of the adult.

Blood.-Hrmaturia may arise from various causes: in brematochyluria, of which the parasitic origin is so well known, in cancer or lithiasis of the kidneys; in purpura, in chronic enteritis, in some eruptive fevers, in acute infectious diseases, in Winckel's disease. and in the dyscrasin peculiar to the new-born child, and the pathological substratum of which consists-according to Beckmann and contrary to Pollock-in the accumulation of corpuscles in the tubes through "thrombosis" of the vessels of the kidneys and consecutive extravasation. J. Thomson saw hrematuria in a child two years old suffering from scurvy, Monti saw it in a child affected with a chronic eczema and itch or in suckling babes who took a sulphurous bath daily during more than an hour. And, finally, in every hyperamic state of the kidneys streaks of blood in the urine as well as in travmatic lesions of any point of the uropoietio system. The examination for the determination of germs (Koch's, Löfller's bacillus, dc.) is made according to the well known rules of bacteriology.

The urine in carious f.rms of disease.--In acute congestion of the kidneys which is the anatomical process corresponding to acute infection there are found renal epithelia, more or less distigured, hyaline casts, a little albumin, and corpuscles, the presence of the latter depending on the existence or nonexistence of hæmorrhages. In passive congestion albumin appears also in small proportion, the volume of urine decreases, it is reddish, and there is an excess of urates. In nephritis generally the colour of the urinary liquid which is acid varies very much; it contains hæmoglobin, albumin, blood corpuscles, hyaline casts, fat and renal epithelia, crystals of uric acid and detritus. In scarlatinal nephritis there are cases (like the cne published by Litten, related by Henocb), in which albuminuria is absent for a long time, without, however, the disease disappearing. In pyelo-nephritis the urine is alkaline, and there are abundance of albumin, pus, large numbers of bacteria and granulo-fatty detritus. Monti bas insisted lately upon the study of the infantile pyelitis, which he considers to be very rare. It is produced often by calculus, seldom by parasites, by echinococcus, by the decomposition of urine retained by obstruction due to hypospadias or phimosis, ivy the use of carbolic and salicylic acids, of Peruvian balsam and of turpentine, by acute infectious diseases, and finally by the migration of the gonococcus from vulvo-vaginitis to the calyx of the kidneys. The symptoms are : (1) fever, not permanent, but preceded with shivering when it exists; (2) cerebral phenomena in an icute state (somnolence, delirium, and violent cephalalgia); (3) pains, not permanent, but when existing being losalized in the loins and irradiating towards the bladder and accompanied with frequent needs of urinating and of defrecating; (4) frequent vomiting in the first period, and continuing whenever tbere is an obstacle to the secretion of the kidneys; (5) the special character of the urine, which is chiefly distinguished by its purulence, its aspect, and acidity; (6) the urinary sediment, which contains pus, epithelial cells from the renal calyx; blood corpuscles and numerous bacterla; (7) cederna of the face, which sometimes may recur; and (8) emaciation, which in chronic pyelitis (?) is very great. Presenting an acute and chronic form (the later in most cases) infantile pyelitis is due mainly to calculus and rapid obliteration of the ureters. In rachitis, according to the observations of several authors, the quantity of phosphates, albumin, and salts of calcium is small, but lactic acid is present. In leukrmia there is an excess of uric acid, of hypoxanthin (?), hyaline casts, and albumin. In chyluria, which never occurs in the first period of childhood, the urine is acid, albuminous, white, coagulates easily, and has a density from 1005 to 1025 . When treated with chloroform it grows red, presenting three well-defined strata after a few hours' rest; one at the bottom, which is whitish; the middle one is rose-coloured and at the top one the urine is normal and clear. The albumin an $x$ the fat being extracted there is a formation of crystals 
of nitrate of urea. The microscope shows blood globules and fat, hyaline casts, crystals of phosphates, epithelial cells, and embryos of filaria sanguinis hominis. In whoopingcough, according to a recent communication from Blumenthal and Hippus, ${ }^{2}$ lrom the beginning to the acme of the disease the urine is pale yellow in colour, very acid, of high specific weight, and perhaps to exaggerated leucocytosis is due the remarkable deposit of free uric acid. For early diagnosis, which is always difficult, these characters of the urine in whooping-cough are very note worthy, but they disappear under the action of antipyretic substances and of complications of the disea:e. In tetimus Oddo found indicanuria, phosphaturia with inversion (alkaline phosphates 2086 and earthy phosphates $0 \cdot 0 \cdot 17$ ), and there was no albumin. This was observed in a child eighteen months old, whose disease had begun with anasarca and retention of urine. In chronic cases of gastro-enteritis in children Felsenthal and Bernhard ${ }^{3}$ found single albuminuria or accompanied with hyaline and granular casts, epithelial matter, mucus, red corpuscles, leucocytes, and sometimes indican. Post-mortem examination showed the lesions of parenchymatous nephritis. In infantile splenic anæmia estimating uric acid by Haycraft's process, the following conclusions will be arrived at: (1) the quantity of uric acid is not in constant relation with that of the urea: (2) in febrile urine the uric acid reaches a maximum of 0.75 gramme per litre; (3) the average in febrile urine is 1.27 grammes per litre and in the apyretic is 067 gramme; and (4) the increase of uric acid in infectious splenic anrmia enhances the importance given to the theory according to which such is not a transitory form of the urea, but a product of the material exchange of the leucocytes. The urine must be carefully examined in the course of many diseases, specially in diseases of the uropoietic system, in scarlet fever, and diphtheria. The diagnosis of various affections of the uropoietic system in early life (hydronephrosis, nephritic abscess, \&c.) is based on the same data as the aduit. But it is necessary to say that cases of tumour of the kidners can be easily recognised, because, owing to the distension of the colon in children, the colon is pressed against the abdominal parietes, where it remains in relief over the tumour and gives a tympanitic sound when percussed.

\section{A CASE OF DEEP-SEATED TROPICAL ABSCESS OF THE LIVER TREATED \\ BY TRANS-THORACIO HEPA- TOTOMY; RECOVERY.}

Bx BYROM BRAMWELL, M.D., F.R.C.P. EDIN., AND

HAROLD J. STILES, F.R.C.S. EDIN.

THE AIEDICAL HISTORY OF THE CASE AND DIAGNOSIS BY DR. BYRoM BRAMWELiL.

A STRONG, muscular man aged twenty-eight years was seen with Dr. Curtis Whyte of Dalkeith and Dr. T. W. Dewar on Oct. 8th, 1895. The patient stated that he had enjoyed perfect health until about six years ago, when he suffered from a rather severe attack of gonorrhoal arthritis affecting especially the knee, both ankles, and the toes. During this illness he was confined to bed for nearly a month and was afterwards treated for some weeks at Buxton. The following spring he again suffered from rheumatism in both ankles and was again treated at Buxton. The rheumatism then gradually left him and he had been free from it ever since. In June, 1894, he went to Lagos on the West Coast of Africa. He described Lagos as a flat, swompy, stinking, fever-breeding place, with no safer watersalply than the rain collected from the roofs of the houses. A month after reaching the colony be was seized with fever of a malarial type; the febrile attacks recurred at longer ox shorter intervals, and usually lasted for two or three days at a time. In April of the following year (1895) he was seited with a severe attack of dysentery. 'This necessitated his remoral to hospital, where he remained three weeks. Prom hospital he was conveyed directly to the ship which brought him home. He derived great benefit from the voyage and stated that on his arrival in this country in June, 1895, he was perfectly well. He remained in good health until the end of August, when while away from home on a holiday he was attacked with severe dysenteric diarrbcea. He returned home looking and feeling ill. He was seen by Dr. Whyte on Sept. 4th. The diarrhca soon yielded to treatment, but some days afterwards he began to complain of intermittent pains in the right shoulder and of a catching pain in the right hypochondriac region at a point corresponding to the junction of the sixth and seventh right costal cartilages with the sternum. The pain in the bypochondriac region was increased by taking a long breath laughing, or yawning. It was so much aggravated by laughing that he was obliged to quit the room whenever there was any joking going on. This pain continued not. withstanding treatment. On the evening of Sept. 20 th he was seized with a chill while out walking and on bis return home he had a distinct rigor. The temperature ran up to $103^{\circ} . \mathrm{F}$ The rigor was followed by profuse perspiration. He was now kept in bed and placed on quinine-five grains four times daily. But as the febrile disturbance persisted in spite of the quinine, and as the patient complained on sereral occasions during the next fortnight of slight chilliness not amounting to distinct rigors, Dr. Whyte and Dr. Dewar began to suspect that he was probably suffering from an abscess of the liver, although no local signs of such a con. dition were discoverable. During this period night sweats were frequent; the temperature always ran up to $101^{\circ}$ or $101.5^{\circ}$ at night, but was usually normal in the morning; the appetite became poor, but the tongue remained clean; there was some loss of flesh. On Oct. 8th I was asked to see the patient in consultation with Dr. Whyte and Dr. Dewar. The most careful examination failed to detect any physical evidence of local disease. The abdominal and thoracic organs all appeared to be normal. The liver was not enlarged and there was no localised tenderness even on firm pressure over any part of the organ. The pulse frequency was only slightly increased; the respirations numbered 16 per minute; the temperature at the time of my visit was slightly below the normal ; the tongue was clean, the appetite was poor, and the bowels were regular. The patient had, since his illness commenced, got a little thinner, but there was certainly no emaciation. The evening temperature bad for some weeks previously been distinctly elevated; there bad been several attacks of chilliness, followed by sweating and one definite rigor. Notwithstanding the absence of any enlargement of the liver and of any tenderness on pressure over the organ I agreed with Dr. Whyte and Dr. Dewar in thinking that the patient was in all probability suffering from an abscess of the liver. This opinion was based on the following line of argument: (1) that the patient was suffering from fever of a hectic type, gradual and progressive emaciation, and occasional attacks of chilliness, hardly amounting to distinct rigors ; (2) that the febrile disturbance was irregular in type (in other words, not distinctly malarial), that it was uninfluenced by quinine, and that there was no definite enlargement of the spleen; (3) that the patient had suffered from severe tropical dysentery: (4) that the patient complained of pain in the right shoulder and of a catching pain in the right hypochondriac region at the junction of the sixth and seventh costal cartilages with the sternum; (5) that the most careful examination failed to detect any evidence of disease in the lungs, heart, or any other organ capable of accounting for the symptoms: and (6) that there was notbing either in the personal condition of the patient, his previous state of bealth, or the family history suggestive of tubercle, acute tuberculosis being one of the conditions which was naturally thought of as a possible cause of the symptoms. For the reasons given above I concluded:- Firstly, that the febrile disturbance was not due to malaria, to tubercle, or to ulcera. tive endocarditis ; further, there was no suspicion of typhoid fever. Secondly, that it was apparently due to some internal suppuration; and thirdly, since there was no discorerable local lesion in any other organ (negntive evidence), and because $(a)$ of the very definite history of dysentery, and (b) of the presence of pain in the right shoulder and right hypochondrium (positive evidence), that, notwithstanding the absence of any positive enlargement of the liver, the internal suppuration, which we believed to be present and to be the cause of the fever, was in a!l probability situated in the liret. Believing, then, that the case was one of hepatic abscess we decided that if the symptoms did not subside after further 